\title{
Prevalence and factors associated with convulsive status epilepticus in Africans with epilepsy OPEN
}

Symon M. Kariuki, MSc Angelina Kakooza-

Mwesige, MD

Ryan G. Wagner, MSc

Eddie Chengo, MSc

Steven White, FRCP

Gathoni Kamuyu, MSc

Anthony K. Ngugi, PhD Josemir W. Sander, FRCP Brian G.R. Neville, FRCP Charles R.J. Newton, MD For the SEEDS Writing Group

Correspondence to Dr. Kariuki: skariuki@kemri-wellcome.org

Supplemental data at Neurology.org

\section{ABSTRACT}

Objective: We conducted a community survey to estimate the prevalence and describe the features, risk factors, and consequences of convulsive status epilepticus (CSE) among people with active convulsive epilepsy (ACE) identified in a multisite survey in Africa.

Methods: We obtained clinical histories of CSE and neurologic examination data among 1,196 people with ACE identified from a population of 379,166 people in 3 sites: Agincourt, South Africa; IgangaMayuge, Uganda; and Kilifi, Kenya. We performed serologic assessment for the presence of antibodies to parasitic infections and HIV and determined adherence to antiepileptic drugs. Consequences of CSE were assessed using a questionnaire. Logistic regression was used to identify risk factors.

Results: The adjusted prevalence of CSE in ACE among the general population across the 3 sites was 2.3 per 1,000, and differed with site ( $<<0.0001)$. Over half (55\%) of CSE occurred in febrile illnesses and focal seizures were present in 61\%. Risk factors for CSE in ACE were neurologic impairments, acute encephalopathy, previous hospitalization, and presence of antibody titers to falciparum malaria and HIV; these differed across sites. Burns (15\%), lack of education (49\%), being single (77\%), and unemployment (78\%) were common in CSE; these differed across the 3 sites. Nine percent with and 10\% without CSE died.

Conclusions: CSE is common in people with ACE in Africa; most occurs with febrile illnesses, is untreated, and has focal features suggesting preventable risk factors. Effective prevention and the management of infections and neurologic impairments may reduce the burden of CSE in ACE. Neurology ${ }^{\circledR} 2015 ; 84: 1838-1845$

\section{GLOSSARY}

$\mathbf{A C E}=$ active convulsive epilepsy; $\mathbf{A E D}=$ antiepileptic drug; $\mathbf{B M I}=$ body mass index; $\mathbf{C l}=$ confidence interval; $\mathbf{C S E}=$ convulsive status epilepticus; KDH = Kilifi District Hospital; $\mathbf{O R}=$ odds ratio.

Convulsive status epilepticus (CSE) is a common and serious complication of epilepsy and of acute symptomatic and febrile seizures. It occurs in $25 \%-30 \%$ of people with active convulsive epilepsy (ACE) $)^{1,2}$ and is dependent upon the underlying etiology and adherence to antiepileptic drugs (AEDs). ${ }^{3}$ CSE among people with epilepsy in the United States is associated with a longterm case fatality of over $20 \%$.

ACE is common in Africa, ${ }^{5}$ and the proportion with CSE is higher given the underlying etiology and large treatment gap. ${ }^{6}$ There are few population-based studies of CSE in Africa, and

From Kenya Medical Research Institute-Wellcome Trust Research Programme (S.M.K., E.C., G.K., A.K.N., C.R.J.N.), Kilifi, Kenya; Nuffield Department of Medicine (S.M.K.), University of Oxford, UK; Studies of Epidemiology of Epilepsy in Demographic Surveillance Systems (SEEDS)-INDEPTH Network (A.K.-M., R.G.W., E.C., G.K., A.K.N., C.R.J.N.), Accra, Ghana; Iganga-Mayuge Health and Demographic Surveillance System (A.K.-M.), Iganga; the Department of Paediatrics and Child Health (A.K.-M.), Makerere University College of Health Sciences, Kampala, Uganda; MRC/Wits Rural Public Health and Health Transitions Research Unit (Agincourt) (R.G.W.), School of Public Health, Faculty of Health Sciences, University of the Witwatersrand, Johannesburg, South Africa; Epidemiology and Global Health (R.G.W.), Department of Public Health and Clinical Medicine, Umeå University, Sweden; the Neurophysiology Department (S.W.), Great Ormond Street Hospital for Children, London; the Neurosciences Unit (B.G.R.N., C.R.J.N.), UCL Institute of Child Health, London, UK; Population Health Sciences/ Research Support Unit (A.K.N.), Faculty of Health Sciences, Aga Khan University (East Africa), Nairobi, Kenya; NIHR University College London Hospitals Biomedical Research Centre (J.W.S.), UCL Institute of Neurology, Queen Square, London; Epilepsy Society (J.W.S.), Bucks, UK; Stichting Epilepsie Instellingen Nederland-SEIN (J.W.S.), Heemstede, Netherlands; Clinical Research Unit (C.R.J.N.), London School of Hygiene and Tropical Medicine; and the Department of Psychiatry (C.R.J.N.), University of Oxford, UK.

Coinvestigators are listed on the Neurology ${ }^{\circledR}$ Web site at Neurology.org.

Go to Neurology.org for full disclosures. Funding information and disclosures deemed relevant by the authors, if any, are provided at the end of the article. The Article Processing Charge was paid by the Wellcome Trust.

This is an open access article distributed under the Creative Commons Attribution License, which permits unrestricted use, distribution, and reproduction in any medium, provided the original work is properly cited. 
most of the available hospital-based studies probably underestimate the burden. The incidence of CSE in children admitted to a Kenyan hospital was 2-5 times that in London and $6 \%$ of these cases occurred in children with established epilepsy ${ }^{6,7}$; many do not attend hospital.

Risk factors for CSE are widely studied, ${ }^{8}$ but it is unclear whether these differ in ACE in Africa. The few available studies from developed countries have focused on epilepsyrelated risk factors of $\mathrm{CSE}^{1}$; other infectious risk factors of CSE may be important among people with epilepsy from low-income countries, where the etiology of epilepsy is different and the treatment gap is high. ${ }^{9}$ The clinical features of CSE and medical and psychosocial consequences may also differ.

We documented the medical history of CSE among people with ACE in 3 African sites to estimate the lifetime prevalence, determine associations with risk factors and clinical features, and examine case fatality, burns, and social factors. We further examined whether there was heterogeneity in clinical features and risk factors across different ecological sites.

METHODS Study population. Cases of CSE were identified in community surveys of ACE conducted between August 2008 and April 2011 as part of a multisite study of epilepsy. ${ }^{5}$ The present analysis includes 3 sites: Agincourt, South Africa; Iganga, Uganda; and Kilifi, Kenya (http://www.indepth-network.org/), where reliable histories of CSE among people with ACE were obtained. Histories of CSE among people with ACE were obtained from the participants, relatives, or witnesses, with further questions on whether CSE was associated with a febrile illness or fever. A clinician obtained data on sociodemographic characteristics and medical history and performed a neurologic examination. Experienced EEG technicians performed a 16 leadchannel EEG using the standard 10-20 montage system (figure 1), read by an experienced EEG technician (E.C.) in consultation with a neurophysiologist (S.W.), who reviewed some recordings to confirm consistency. We followed up individuals with CSE for a further 3 years to observe survivorship.

Definition of terms. We defined CSE as a history of convulsive seizures lasting for 30 minutes or more with impaired consciousness, or intermittent seizures lasting for 30 minutes or more without regaining consciousness in between the seizures. ${ }^{10}$ The definitions utilized culturally appropriate events to time the seizures for those without watches or mobile phones, such as whether a seizure lasted longer than the time taken to boil a pot of maize, duration of a news program, or religious sermon, all of which last $\geq 30$ minutes.

We classified epileptic seizures as focal, generalized, or others according to recent International League Against Epilepsy recommendations. ${ }^{11}$ We categorized seizure frequency into daily, weekly, monthly, or yearly.

We defined children as those aged 0-18 years. We defined a perinatal adverse event as delay in crying, breathing, or breastfeeding after birth, but was included only in those aged 18 years and below, to reduce recall bias. We defined acute encephalopathy as coma related to an acute malarial, viral, or bacterial illness. Cognitive impairment was based on ability to follow standardized instructions during neurologic examination. We defined malnutrition as height for age $z$ scores below -2 for those $0-10$ years, body mass index (BMI) (weight/height ${ }^{2}$ ) in the lower 5 th percentile for those $11-19$ years, and BMI $<18.5$ for adults. ${ }^{2,12}$

Investigations. In a random proportion of people [selected by RAND () command in MySQL (Oracle, Redwood Shores, CA)] with ACE and a history of CSE (figure 1), G.K. analyzed blood for antibodies to Onchocerca volvulus, HIV, Taenia solium, Toxocara canis, Plasmodium falciparum schizonts, and Toxoplasma gondii. The commercial kits, technique used, cut-off criteria, and sensitivities and specificities associated with detection of each organism were described previously. ${ }^{13}$ Adherence to AEDs was measured in blood using a technique described previously. ${ }^{14}$

Figure 1 Investigations performed in convulsive status epilepticus in active convulsive epilepsy

People with ACE in Agincourt ( $\mathrm{N}=250)$, Iganga $(\mathrm{N}=224)$, and Kilifi $(\mathrm{N}=722)$

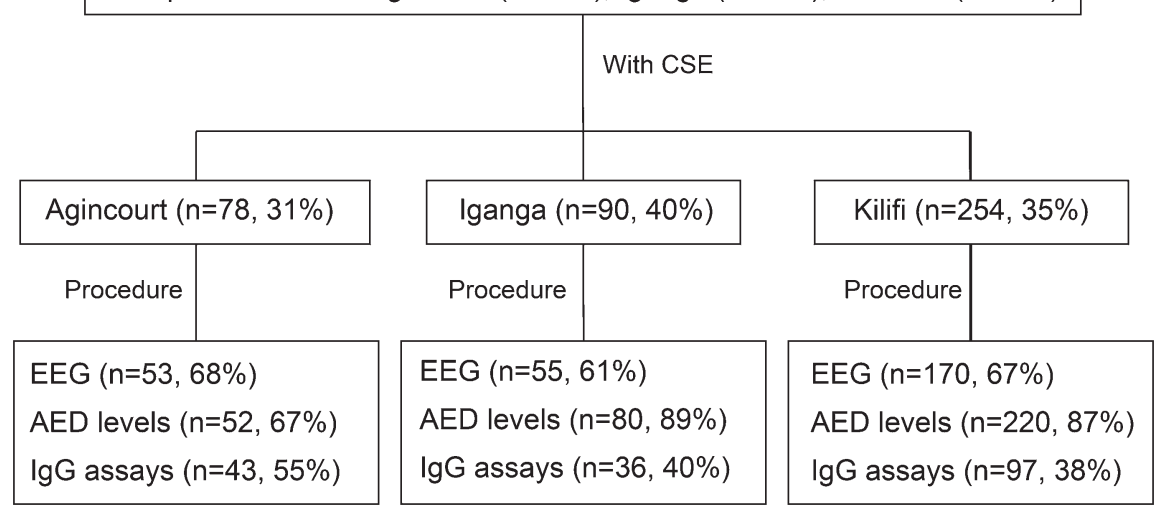

People with convulsive status epilepticus (CSE) in active convulsive epilepsy (ACE) who had EEG performed, and antiepileptic drug (AED) blood levels and antibody titers to parasitic infections and HIV determined. ACE = active convulsive epilepsy; IgG = immunoglobulin $\mathrm{G}$. 
Statistical analysis. We estimated the prevalence of CSE associated with ACE for each center by dividing the number of confirmed cases of CSE by the total number of individuals screened in the survey. The prevalence was adjusted for the sensitivity of the methodology used to identify people with ACE. ${ }^{15}$ In Kilifi, we compared the community estimates with admissions during or prior to the survey using the Kilifi Health and Demographic Surveillance System database, which offers a framework for linking hospital and population data for each person. ${ }^{16}$

We compared those with CSE in ACE with those with ACE without CSE. Pearson $\chi^{2}$ test was used to compare proportions while Student $t$ test or Mann-Whitney, where appropriate, was used to compare continuous variables between groups. Up to 774 people with ACE without CSE were included in the risk factor analysis (table e-1 on the Neurology ${ }^{\circledR}$ Web site at Neurology.org). We used a logistic regression model that included age, sex, site, education, and marital status of parents to compute odds ratios (ORs) for each risk factor. All infections were entered together into the adjusted logistic model to examine their independent association with CSE in ACE. We considered a $p$ value of $\leq 0.05$ significant. Consequences of CSE in those with ACE were compared first with those with ACE without CSE and then with age group-matched community controls without ACE ( $\mathrm{n}=1,025$ for the 3 sites) (table e- 1 ).

Standard protocol approvals, registrations, and patient consents. This project was approved by the Kenyan National Ethical Review Committee as well as the respective Institutional
Review Boards in Uganda and South Africa. Written informed consent was sought from people with epilepsy or caregivers.

RESULTS We identified 422 cases of CSE out of 1,196 people with ACE across the 3 sites, of which $256 / 422(61 \%)$ occurred in children ( $<18$ years) and $211 / 422(50 \%)$ in males. The majority of the cases of CSE in ACE were drawn from Kilifi (254/ 422 [60\%]), with the remainder from Agincourt and Iganga (table 1). Over half (230/422 [55\%]) of the reported CSE cases occurred with a febrile illness and this was similar in generalized and focal epilepsy $(p=$ $0.4)$. The overall adjusted prevalence of CSE associated with ACE among the general population across the sites was 2.3 per 1,000 , being highest in Iganga (2.8 per 1,000) (table 1$)$, and was greatest in adolescents and young adults (figure 2 ).

Status epilepticus and hospital use. Data on use of hospital services by people with CSE in ACE was available only for Kilifi, where 143/254 (56\%) people with CSE associated with ACE in the community sought biomedical care for seizures at Kilifi District Hospital $(\mathrm{KDH})$ at least once. Of these 143

Table 1 Characteristics and prevalence of convulsive status epilepticus in active convulsive epilepsy

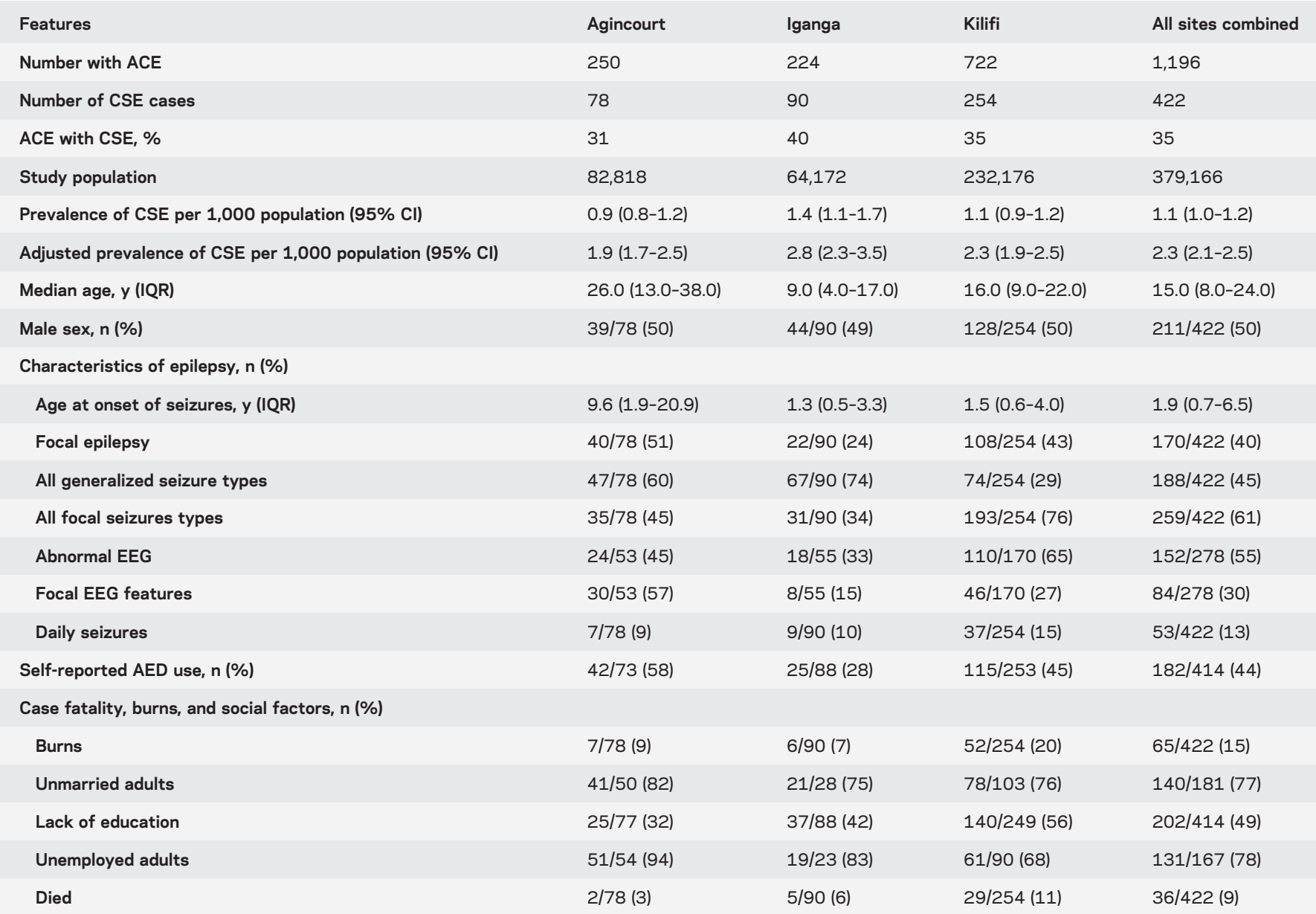

Abbreviations: $\mathrm{ACE}=$ active convulsive epilepsy; $\mathrm{AED}=$ antiepileptic drug; $\mathrm{Cl}=$ confidence interval; $\mathrm{CSE}=$ convulsive status epilepticus; IQR $=$ interquartile range. 


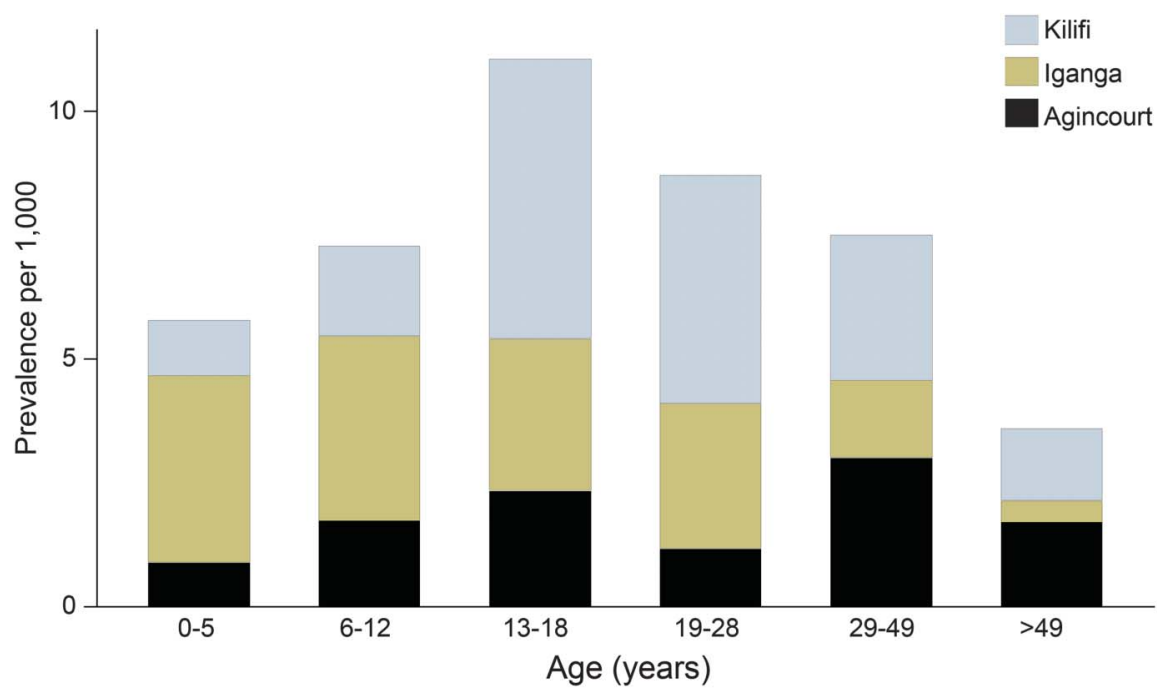

The cumulative prevalence of convulsive status epilepticus in active convulsive epilepsy increased up to 18 years then declined steadily across 3 sites in sub-Saharan Africa.

admissions, 97 (68\%) were children; most were admitted for nonepilepsy reasons. Twelve (12\%) children with CSE in the community had been hospitalized at $\mathrm{KDH}$ more than once. Of the 143 admissions, $46(32 \%)$ were adults, all of whom were admitted with epilepsy-related complications.

Age at onset of seizures. The median (interquartile range) age at onset of seizures in years for those with ACE and CSE was 1.9 (0.7-6.5). The onset of febrile CSE was earlier (1.2 [0.5-6.3]) than that of nonfebrile CSE (6.7 [1.4-18.6]; $p<0.0001)$. Seizures in ACE with CSE began earlier in those with a history of febrile seizures $(2.3[0.7-10.0])$ than in those without (4.0 [1.09-15.0]; $p=0.0003$ ). Epileptic seizures began at a younger age in Iganga and Kilifi than in Agincourt (table 1).

Seizure types. Over half $(259,61 \%)$ had focal seizures in ACE with CSE; the proportion was similar in males and females $(p=0.7)$, and in children and adults $(p=0.1)$, but were more common in febrile than nonfebrile CSE (146/220 [66\%] vs 110/198 [56\%]; $p=0.024)$. Focal seizures in CSE differed across sites $(p<0.0001)$, being most common in Kilifi (193/254 [76\%]). Other specific focal seizure types are shown in table e- 1 .

Generalized convulsive and nonconvulsive seizures in ACE with CSE occurred in 188/422 (45\%) study participants and the proportion was similar in males and females $(p=0.8)$ and in children and adults $(p=0.7)$. The proportion of generalized seizures in CSE differed across the sites $(p<$ $0.001)$, being most common in Iganga $(67 / 90$ [74\%]).
Epileptic seizure semiology and EEG. Of the 278 people with CSE in ACE who had EEG performed, abnormal EEG patterns occurred in 152 (55\%), and abnormalities were similar in children and adults $(p=$ $0.09)$, but differed with site $(p=0.001)$, being commonest in Kilifi (110/170 [65\%]) (table 1). Focal EEG features (defined as focal slowing or epileptiform discharges) were observed in 84/278 (30\%) people with CSE in ACE and did not differ between febrile and nonfebrile CSE $(p=0.4)$. The highest proportion of focal EEG features was seen in Agincourt (30/ $53[57 \%])$, with differences across the sites $(p<$ $0.0001)$. Of 125 people reported to have generalized epileptic seizure semiology in ACE with CSE, 42 (34\%) had focal EEG features.

Seizure frequency and AED use. Seizures occurred daily in $53 / 422(13 \%)$, weekly in $46 / 422(11 \%)$, monthly in $149 / 422(35 \%)$, and yearly in $174 / 422(41 \%)$ people with CSE in ACE (table e-1). The seizure frequency was not associated with febrile $\operatorname{CSE}(p=$ $0.1)$. Seizure frequency varied with site $(p<0.001)$.

AED use was reported by $182 / 414$ (44\%) people with CSE in ACE, and the use varied with site $(p=$ $0.001)$, being commonest in Agincourt (42/73 [58\%]) (table 1). Blood levels assays showed that 95/352 (27\%) were on AEDs (phenobarbital, carbamazepine, or phenytoin), representing a sensitivity of 78/155 (50\%) for self-reported use. AED use was not associated with seizure frequency for the self-reported use (univariate OR $=0.89$ [95\% confidence interval (CI) $0.77-$ 1.03]; $p=0.137$ ) but adherence as measured in the blood was associated with a reduction in seizure frequency $(\mathrm{OR}=0.84$ [95\% CI 0.70-0.99]; $p=0.048)$. 
Risk factors associated with status epilepticus. Several factors were associated with a higher probability of having CSE in those with ACE compared to those with ACE without CSE in the pooled analysis across all the sites. These included history of acute encephalopathy, neurologic and learning impairments, and presence of exposure to malaria and HIV in plasma (tables 2 and 3). History of previous hospitalization appeared to be protective against developing CSE in ACE. Site-specific risk factors are shown in table e-2.

A summated score for number of infections detected across all sites was independently associated with CSE in ACE for antibodies to malaria schizonts $(\mathrm{OR}=1.84$ [95\% CI 1.16-2.93]; $p=0.010)$ and $\mathrm{HIV}(\mathrm{OR}=2.55$ [95\% CI 1.22-5.30]; $p=0.012)$. Associations for individual infections are shown in table 3. These infections were independently associated with CSE in ACE in Kilifi (OR = 3.47 [95\% CI $1.61-7.45] ; p=0.001$ for malaria and $\mathrm{OR}=3.49$ [95\% CI 1.10-11.08]; $p=0.034$ for HIV), but not the other 2 sites (table e-2).

Consequences of CSE in those with ACE. Case fatality proportion. After 3 years, 36/422 (9\%) with CSE in ACE had died, in similar proportions to those with ACE without CSE (77/774 [10\%]; $p=0.4)$ but with differences across sites $(p<0.026)$, being most common in Kilifi (29/254 [11\%]) (table 1). Case fatality was not associated with adherence to AEDs as measured in blood $(p=0.4)$, but with cognitive impairments $(p<0.001)$.

Burns. Burns were reported in 65/422 (15\%) people with CSE in ACE, similar to that of those with
ACE without CSE (142/762 [19\%]; $p=0.2)$, but greater than community controls without ACE (58/ $1,016[6 \%] ; p<0.001)$. The proportion with burns differed across the sites $(p=0.002)$. Surprisingly, adherence to AEDs as measured in blood was positively associated with burns (OR $=1.70[95 \% \mathrm{CI}$ 1.22-2.38]; $p=0.002$ ).

Lack of education. Lack of formal education was reported in 202/414 (49\%) people with CSE in ACE, similar to those with ACE without CSE (337/763 [44\%]; $p=0.1$ ), but was greater than in community controls without ACE (272/1,010 [27\%]; $p<$ $0.001)$. Lack of formal education differed across the sites $(p<0.001)$, being more common in Kilifi (140/ 249 [56\%]) (table 1).

Marriage prospects. Being single was reported in 140/181 (77\%) adults with CSE in ACE, greater than in those with ACE without CSE (242/390 [62\%]; $p<0.0001)$ and in community controls without ACE (195/475 [41.1\%]; $p<0.001)$. Being single was significantly associated with adherence to AEDs as measured in blood (univariate $\mathrm{OR}=1.65$ [95\% CI 1.25-2.17]; $p<0.0001)$. Being unmarried did not differ across the sites $(p=0.7)$ (table 1 ).

Unemployment. Unemployment in adults with CSE in ACE was similar to those without CSE (131/167 [78\%] vs 291/405 [72\%]; $p=0.1$ ), but significantly greater than that of community controls without ACE (297/487 [61\%]; $p<0.001)$. Unemployment was not associated with adherence $(p=0.9)$. Unemployment differed across the sites $(p<0.0001)$, being most common in Agincourt (51/54 [94\%]) (table 1).

\begin{tabular}{|c|c|c|c|c|c|c|}
\hline $\begin{array}{l}\text { Pooled univa } \\
\text { active convu }\end{array}$ & $\begin{array}{l}\text { and adjusted analysis } \\
\text { epilepsy for all sites ce }\end{array}$ & $\begin{array}{l}f \text { the medical risk fac } \\
\text { mbined }\end{array}$ & ors associated with co & ulsive st & s epilepticus among & ple with \\
\hline Variable & People without CSE (\%) & People with CSE (\%) & Unadjusted OR (95\% Cl) & $p$ Value & Adjusted OR $(95 \% \mathrm{CI})^{\mathrm{a}}$ & $p$ Value \\
\hline \multicolumn{7}{|l|}{ Medical history } \\
\hline Febrile seizures & 90/762 (12) & $54 / 415(13)$ & $1.12(0.77-1.60)$ & 0.548 & $1.13(0.77-1.64)$ & 0.536 \\
\hline Seizures in siblings & 60/768 (8) & 33/421 (8) & $1.00(0.64-1.56)$ & 0.987 & $0.87(0.54-1.40)$ & 0.563 \\
\hline Adverse perinatal events & 29/358 (8) & 23/249 (9) & $1.15(0.65-2.05)$ & 0.623 & $1.16(0.65-2.08)$ & 0.614 \\
\hline Abnormal pregnancy & $57 / 358(16)$ & $44 / 249$ (18) & $1.13(0.74-1.74)$ & 0.569 & $1.06(0.68-1.67)$ & 0.785 \\
\hline Acute encephalopathy & 9/765 (1) & $190 / 418(45)$ & 70.00 (35.29-138.83) & $<0.0001$ & 73.57 (35.45-152.67) & $<0.001$ \\
\hline Previous hospitalization & $458 / 768(60)$ & $203 / 420(48)$ & $0.63(0.49-0.80)$ & $<0.0001$ & $0.69(0.54-0.89)$ & 0.004 \\
\hline Drug abuse & $61 / 768(8)$ & $22 / 419$ (5) & $0.64(0.39-1.06)$ & 0.084 & $0.78(0.48-1.33)$ & 0.363 \\
\hline Visits traditional healers & $474 / 726(65)$ & $278 / 390(71)$ & $1.32(1.01-1.72)$ & 0.042 & $1.30(0.98-1.72)$ & 0.071 \\
\hline Self-reported AED use & $317 / 754$ (42) & $182 / 414(44)$ & $1.08(0.85-1.38)$ & 0.526 & $1.18(0.91-1.52)$ & 0.219 \\
\hline
\end{tabular}

Abbreviations: $\mathrm{AED}=$ antiepileptic drug; $\mathrm{Cl}$ = confidence interval; $\mathrm{CSE}$ = convulsive status epilepticus; $\mathrm{OR}=$ odds ratio.

a Adjusted for age, sex, site, lack of education, and marital status for adults. 
Table 3 Pooled univariate and adjusted analysis of the medical and laboratory risk factors associated with convulsive status epilepticus among people with active convulsive epilepsy for all sites combined

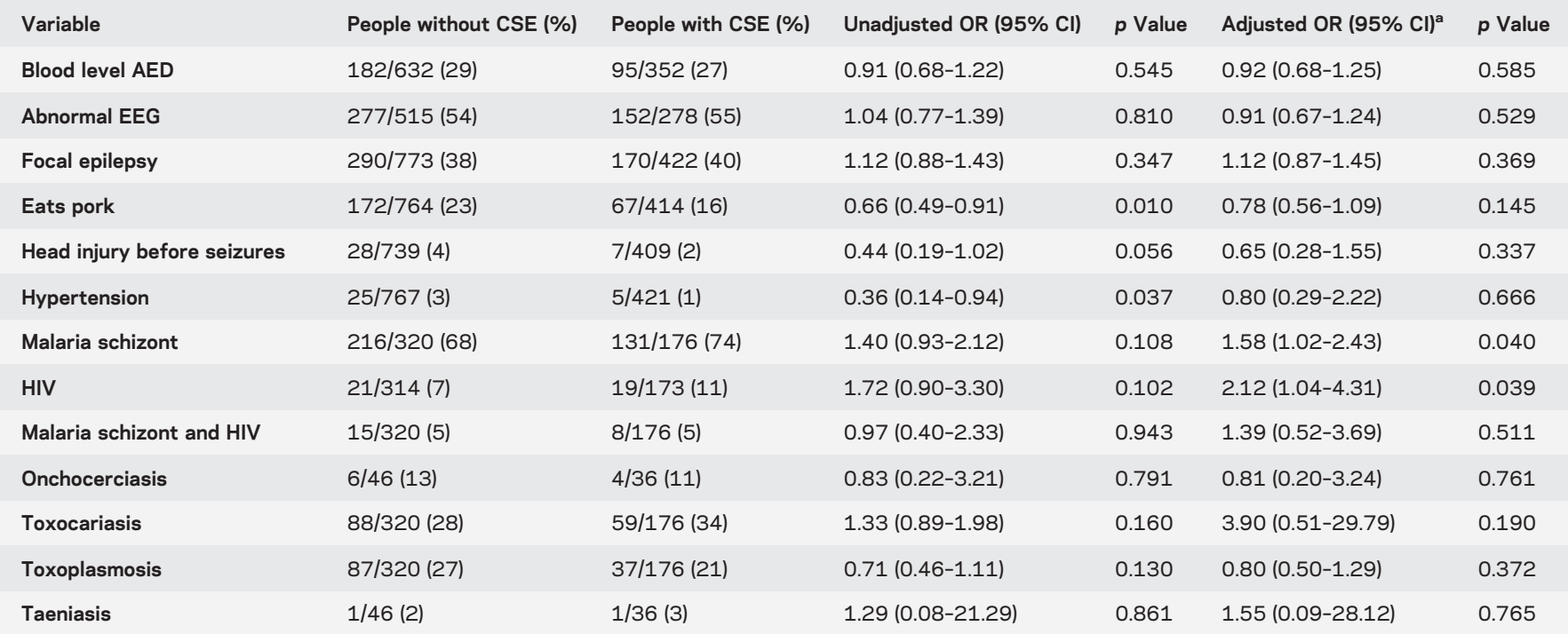

Abbreviations: $\mathrm{AED}=$ antiepileptic drug; $\mathrm{Cl}=$ confidence interval; $\mathrm{CSE}=$ convulsive status epilepticus; $\mathrm{OR}=$ odds ratio.

${ }^{a}$ Adjusted for age, sex, site, lack of education, and marital status for adults.

DISCUSSION The adjusted prevalence of CSE in people with ACE in Africa is high (2.3 per 1,000), and the true burden of all CSE may be greater, as these estimates only represent that associated with ACE, which does not include acute symptomatic seizures and deaths after an episode of CSE. CSE was associated with history of acute encephalopathy, an absence of previous hospitalization, underlying neurologic impairments, and presence of antibody titers to falciparum malaria and HIV. Risk factors associated with CSE in ACE differed across the sites.

CSE is more common in Africa than in other parts of the world. ${ }^{17}$ Our estimates of CSE associated with epilepsy are comparable with those reported in studies from the United States $(0.5-2.5$ per 1,000$),{ }^{1,18}$ where nonconvulsive epilepsies may have been included in some studies and case ascertainment may have been better as they are less hampered by logistical constraints. The prevalence was highest in Iganga, where family history of seizures was an important risk factor, suggesting shared environmental or genetic factors. Use of AEDs and hospital services in this study were low, suggesting the need to apply educational interventions to encourage use of health services for management of prolonged seizures. ${ }^{19}$

Among people with CSE in ACE, seizures began earlier in those with febrile illnesses than in those without, probably related to infectious causes of CSE in childhood. ${ }^{7,20}$ An early occurrence of CSE for those with a history of febrile illness may also suggest a genetic susceptibility for acute febrile seizures. $^{21,22}$ The difference in age at onset between sites suggests different age-dependent risk factors, some of which may increase case fatality rate, particularly in children with CSE. ${ }^{4}$

People with ACE with CSE in Agincourt and Iganga had a particularly high proportion of generalized seizures, but a third had focal EEG features and could have rapidly generalized. Generalized prolonged seizures are thought to be associated with a good outcome with appropriate treatment, ${ }^{23}$ while focal seizures may be a marker of underlying preventable causes or regional atrophy on MRI caused by prolonged seizures. ${ }^{24}$

Neurologic and cognitive deficits were important risk factors of CSE in those with ACE, and could be markers of underlying brain damage. A history of acute encephalopathy was associated with CSE, as would be expected in those hospitalized with CNS infections, ${ }^{7}$ also supported by significant presence of antibodies to falciparum malaria and HIV. Previous use of hospital facilities appeared protective against CSE, and this may be explained by some people who are likely to live near the hospitals or adhere to AEDs. Visiting a traditional healer may have delayed conventional treatment, with seizures leading to CSE in some people with ACE.

Exposure to falciparum malaria and HIV was associated with CSE in ACE and these 2 infections may interact. ${ }^{25}$ We previously found that over half of hospitalized CSE cases in children was related to malaria ${ }^{7}$ and recently demonstrated that over $90 \%$ episodes of CSE in parasitemic children are caused by malaria. ${ }^{26}$ The differences in risk factors across sites suggest that specific preventative strategies and treatment options should be applied for different sites; alternatively, this 
may be explained by the small numbers at some sites, different field assistants asking questions, and differences in medical services. These results may only apply in other African countries with similar ecological, cultural, and sociodemographic characteristics.

Medical and psychosocial detrimental consequences were similar in those with ACE with and without CSE but more common than in the general population. The mortality was low because this represents a cohort who have survived CSE, which occurred during childhood and was associated with febrile illnesses. ${ }^{7}$ Case fatality was lower than in CSE in Richmond, Virginia, where there may have been more accurate documentation and longer follow-up period than in our study. This African cohort included CSE survivors during the survey. ${ }^{4}$ Case fatality was increased in those with cognitive impairment, suggesting that underlying comorbidities, including psychiatric problems, ${ }^{27}$ may increase the risk of death in people with CSE in ACE. Adherence to AEDs appeared to increase the risk of some social consequences of CSE, supporting the hypotheses that these occur in severe epilepsy. Those using AEDs and with severe epilepsy may be stigmatized, affecting marriage prospects.

The strength of this work is that we used community data from multiple sites, and there is detailed description of risk factors and consequences of CSE. The study reported estimates for CSE in ACE only, and yet non-CSE may account for over $50 \%$ of the cases of status epilepticus. ${ }^{28}$ Recall bias and case fatality prior to the survey could have caused underestimation of prevalence. This is a cross-sectional study and future prospective community incidence studies of CSE and its consequences are required to provide reliable estimates.

CSE is common in people with ACE in Africa, with estimates greater than in high-income countries, and is associated with focal clinical features suggestive of underlying preventable causes. Underlying neurologic impairments and CNS infections such as falciparum malaria are important associations with CSE in people with ACE. Some associations differ across countries, suggesting different strategies and control measures are required for specific sites. CSE in ACE is associated with detrimental effects, similar to that seen in ACE without CSE, but greater than in the general population and thus should be addressed. Future prospective studies are required to provide reliable estimates and explore feasible control and treatment measures.

\section{AUTHOR CONTRIBUTIONS}

Symon M. Kariuki: drafting/revising the manuscript, study concept or design, analysis or interpretation of data, accepts responsibility for conduct of research and final approval, statistical analysis. Angelina Kakooza-Mwesige: drafting/revising the manuscript, study concept or design, analysis or interpretation of data, accepts responsibility for conduct of research and final approval, acquisition of data, study supervision. Ryan G. Wagner: drafting/revising the manuscript, accepts responsibility for conduct of research and final approval, acquisition of data, study supervision. Eddie Chengo: drafting/revising the manuscript, study concept or design, accepts responsibility for conduct of research and final approval, acquisition of data, study supervision. Steven White: drafting/ revising the manuscript, analysis or interpretation of data, accepts responsibility for conduct of research and final approval. Gathoni Kamuyu: analysis or interpretation of data, accepts responsibility for conduct of research and final approval, acquisition of data, study supervision. Anthony Ngugi: drafting/revising the manuscript, study concept or design, accepts responsibility for conduct of research and final approval. Ley Sander: drafting/revising the manuscript, study concept or design, analysis or interpretation of data, accepts responsibility for conduct of research and final approval. Brian Neville: drafting/revising the manuscript, study concept or design, accepts responsibility for conduct of research and final approval, study supervision. Charles Newton: drafting/revising the manuscript, study concept or design, analysis or interpretation of data, accepts responsibility for conduct of research and final approval, acquisition of data, statistical analysis, study supervision, obtaining funding.

\section{ACKNOWLEDGMENT}

The authors thank Dr. Gail Bell for appraising the manuscript and the community members in each site for agreeing to take part in the study. This article is published with the permission of the Director of KEMRI.

\section{STUDY FUNDING}

Supported by the Wellcome Trust, through a Senior Clinical Research Fellowship (083744) to CRJCN. S.M.K. is supported by the Wellcome Trust (099782/Z/12/Z). J.W.S. is supported by the Dr. Marvin Weil Epilepsy Research Fund.

\section{DISCLOSURE}

S. Kariuki, A. Kakooza-Mwesige, R. Wagner, E. Chengo, S. White, G. Kamuyu, and A. Ngugi report no disclosures relevant to the manuscript. J. Sander has received research grants and honoraria from UCB, Eisai, Teva, Lundbeck, and GSK, which are involved in the manufacturing of antiepileptic drugs. B. Neville and C. Newton report no disclosures relevant to the manuscript. Go to Neurology.org for full disclosures.

Received October 9, 2014. Accepted in final form January 9, 2015.

\section{REFERENCES}

1. Hauser WA. Status epilepticus: epidemiologic considerations. Neurology 1990;40(5 Suppl 2):9-13.

2. Kariuki SM, Matuja W, Akpalu A, et al. Clinical features, proximate causes, and consequences of active convulsive epilepsy in Africa. Epilepsia 2014;55:76-85.

3. Towne AR, Pellock JM, Ko D, DeLorenzo RJ. Determinants of case fatality rate in status epilepticus. Epilepsia 1994;35:27-34.

4. DeLorenzo RJ, Pellock JM, Towne AR, Boggs JG. Epidemiology of status epilepticus. J Clin Neurophysiol 1995; 12:316-325.

5. Ngugi AK, Bottomley C, Kleinschmidt I, et al. Prevalence of active convulsive epilepsy in sub-Saharan Africa and associated risk factors: cross-sectional and case-control studies. Lancet Neurol 2013;12:253-263.

6. Newton CR, Kariuki SM. Status epilepticus in subSaharan Africa: new findings. Epilepsia 2013;54(suppl 6):50-53

7. Sadarangani M, Seaton C, Scott JA, et al. Incidence and outcome of convulsive status epilepticus in Kenyan children: a cohort study. Lancet Neurol 2008;7:145-150.

8. Fountain NB. Status epilepticus: risk factors and complications. Epilepsia 2000;41(suppl 2):S23-S30. 
9. Newton CR, Garcia HH. Epilepsy in poor regions of the world. Lancet 2012;380:1193-1201.

10. ILAE. Guidelines for epidemiologic studies on epilepsy: Commission on Epidemiology and Prognosis, International League Against Epilepsy. Epilepsia 1993;34:592-596.

11. Thurman DJ, Beghi E, Begley CE, et al. Standards for epidemiologic studies and surveillance of epilepsy. Epilepsia 2011;52:2-26.

12. Quet F, Rafael F, Ngoungou EB, Diagana M, Druet-Cabanac M, Preux PM. Investigating epilepsy in Africa: 10 years of data collection using a standardized questionnaire in 2,269 peoples with epilepsy. Epilepsia 2011;52:1868-1876.

13. Kamuyu G, Bottomley C, Mageto J, et al. Exposure to multiple parasites is associated with the prevalence of active convulsive epilepsy in sub-Saharan Africa. PLoS Negl Trop Dis 2014;8:e2908.

14. Mbuba CK, Ngugi AK, Fegan G, et al. Risk factors associated with the epilepsy treatment gap in Kilifi, Kenya: a cross-sectional study. Lancet Neurol 2012;11:688-696.

15. Ngugi AK, Bottomley C, Chengo E, et al. The validation of a three-stage screening methodology for detecting active convulsive epilepsy in population-based studies in health and demographic surveillance systems. Emerg Themes Epidemiol 2012;9:8

16. Scott JA, Bauni E, Moisi JC, et al. Profile: the Kilifi Health and Demographic Surveillance System (KHDSS). Int J Epidemiol 2012;41:650-657.

17. Neligan A, Shorvon SD. Frequency and prognosis of convulsive status epilepticus of different causes: a systematic review. Arch Neurol 2010;67:931-940.

18. Wu YW, Shek DW, Garcia PA, Zhao S, Johnston SC. Incidence and case fatality rate of generalized convulsive status epilepticus in California. Neurology 2002;58: 1070-1076.

19. Shorvon S. The treatment of status epilepticus. Curr Opin Neurol 2011;24:165-170.

20. Chin RF, Neville BG, Peckham C, Bedford H, Wade A, Scott RC. Incidence, cause, and short-term outcome of convulsive status epilepticus in childhood: prospective population-based study. Lancet 2006;368: 222-229.

21. Tsuboi T. Genetic analysis of febrile convulsions: twin and family studies. Hum Genet 1987;75:7-14.

22. Kariuki SM, Rockett K, Clark TG, et al. The genetic risk of acute seizures in African children with falciparum malaria. Epilepsia 2013;54:990-1001.

23. Shorvon S. The management of status epilepticus. J Neurol Neurosurg Psychiatry 2001;70:ii22-ii27.

24. Lansberg MG, O’Brien MW, Norbash AM, Moseley ME, Morrell M, Albers GW. MRI abnormalities associated with partial status epilepticus. Neurology 1999;52:1021-1027.

25. Newton CR. Interaction between plasmodium falciparum and human immunodeficiency virus type 1 on the central nervous system of African children. J Neurovirol 2005;11 (suppl 3):45-51.

26. Kariuki SM, Ikumi M, Ojal J, et al. Acute seizures attributable to falciparum malaria in an endemic area on the Kenyan coast. Brain 2011;134:1519-1528.

27. Fazel S, Wolf A, Langstrom N, Newton CR, Lichtenstein P. Premature case fatality rate in epilepsy and the role of psychiatric comorbidity: a total population study. Lancet 2013;382: 1646-1654.

28. Rosenow F, Hamer HM, Knake S. The epidemiology of convulsive and nonconvulsive status epilepticus. Epilepsia 2007;48(suppl 8):82-84.

\section{Neurology ${ }^{\circledR}$ Genetics Call For Papers}

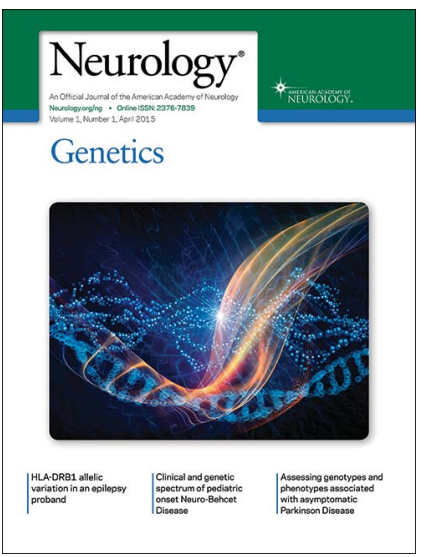

Neurology: Genetics is an open access, online only journal that will provide neurologists with outstanding original contributions that elucidate the role of genetic and epigenetic variation in diseases and biological traits of the central and peripheral nervous system. We welcome all submissions. For more information on how to submit, visit http://www.neurology.org/site/ gen/gen2.xhtml. 


\section{Neurology}

Prevalence and factors associated with convulsive status epilepticus in Africans with epilepsy

Symon M. Kariuki, Angelina Kakooza-Mwesige, Ryan G. Wagner, et al. Neurology 2015;84;1838-1845 Published Online before print April 3, 2015

DOI 10.1212/WNL.0000000000001542

This information is current as of April 3, 2015

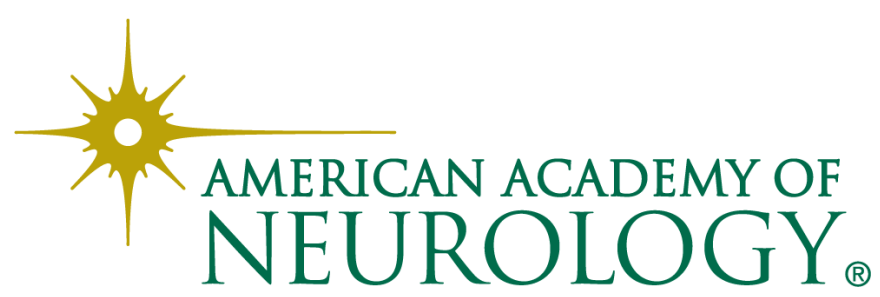




\section{Updated Information \& Services}

\section{Supplementary Material}

\section{References}

Citations

Subspecialty Collections

\section{Permissions \& Licensing}

Reprints including high resolution figures, can be found at: http://n.neurology.org/content/84/18/1838.full

Supplementary material can be found at: http://n.neurology.org/content/suppl/2015/04/03/WNL.0000000000001 542.DC1

http://n.neurology.org/content/suppl/2015/04/03/WNL.0000000000001 542.DC2

This article cites 28 articles, 3 of which you can access for free at: http://n.neurology.org/content/84/18/1838.full\#ref-list-1

This article has been cited by 1 HighWire-hosted articles: http://n.neurology.org/content/84/18/1838.full\#\#otherarticles

This article, along with others on similar topics, appears in the following collection(s):

All Clinical Neurology

http://n.neurology.org/cgi/collection/all_clinical_neurology

All epidemiology

http://n.neurology.org/cgi/collection/all_epidemiology

All Epilepsy/Seizures

http://n.neurology.org/cgi/collection/all_epilepsy_seizures

EEG; see Epilepsy/Seizures

http://n.neurology.org/cgi/collection/eeg_see_epilepsy-seizures

Public health

http://n.neurology.org/cgi/collection/public_health

Status epilepticus

http://n.neurology.org/cgi/collection/status_epilepticus

Information about reproducing this article in parts (figures,tables) or in its entirety can be found online at:

http://www.neurology.org/about/about_the_journal\#permissions

Information about ordering reprints can be found online:

http://n.neurology.org/subscribers/advertise

Neurology ${ }^{\circledR}$ is the official journal of the American Academy of Neurology. Published continuously since 1951, it is now a weekly with 48 issues per year. Copyright @ 2015 American Academy of Neurology. All rights reserved. Print ISSN: 0028-3878. Online ISSN: 1526-632X.

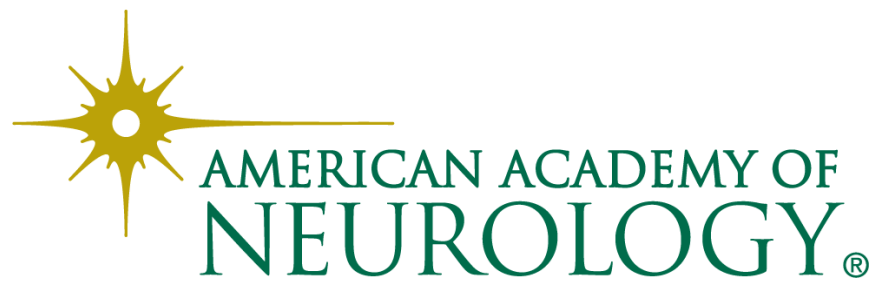

